\title{
Listening to the Thames
}

\author{
Toby Gifford \\ Queensland Conservatorium \\ Griffith University \\ 140 Grey St, Southbank \\ QLD 4101, Australia \\ t.gifford@griffith.edu.au
}

\author{
Simon Linke \\ Australian Rivers Institute \\ Griffith University \\ 170 Kessel's Rd Nathan \\ QLD 4111, Australia \\ s.linke@griffith.edu.au
}

\author{
Leah Barclay \\ Australian Rivers Institute \\ Griffith University \\ 170 Kessel's Rd Nathan \\ QLD 4111, Australia \\ leah.barclay@me.com
}

\section{INTRODUCTION}

Listening to the Thames is an installation revealing the sonic world below the surface of the Thames. Audio from a hydrophone submerged in the Thames is streamed, processed and visualised into a real-time audio-visual installation.

Comprising an interdisciplinary collaboration of freshwater ecology, audio technology, acoustic ecology, electronic composition and sound art; Listening to the Thames draws on the authors' ongoing work in freshwater bioacoustic monitoring (Linke et al. 2013), the acoustic ecology of rivers and the communities they support (Barclay 2013), and soundscape compositions from riverine field recordings (see leahbarclay.com).

Building on artistic explorations of the Thames such as Bill Fontana's (2010) River Sounding, Craig et al. (2009) London's Changing Riverscape and John Eacott's (2012) Flood Tide; and on scientific explorations of rivers through sound such as Anderson et al. (2008) exploration of the Hudson river, and Tonolla et al. (2010) acoustic hydrology investigations; this installation is located in the arts/science nexus, working unveil the hidden underwater environment.

\section{RIVER LISTENING}

In our current state of environmental crisis, biodiversity assessment is critical to understanding the rapid ecological changes taking place across the globe. In the last ten years, there has been a blossoming of non-invasive monitoring involving auditory recordings of the environment. This emerging field is commonly referred to as soundscape ecology and shares many parallels with other fields, including bioacoustics. Soundscape ecology has an array of creative possibilities that have been deeply explored by practitioners including Bernie Krause (2012), Douglas Quin (2002) and Leah Barclay (2013). The literature suggests it will continue expanding within scientific fields, with a particular focus on the importance of soundscape conservation, the impact of noise pollution, and the value of soundscapes to assist with biodiversity analysis. There are now a growing number of international projects and scientific institutions embracing methods of bioacoustics in biodiversity analysis of aquatic environments.

Listening to the Thames is a part of a broader project called River Listening: a practice based research collaboration between Artist-in-Residence Leah Barclay and the Australian Rivers Institute at Griffith University to explore the emerging fields of aquatic bioacoustics and soundscape ecology in river systems.

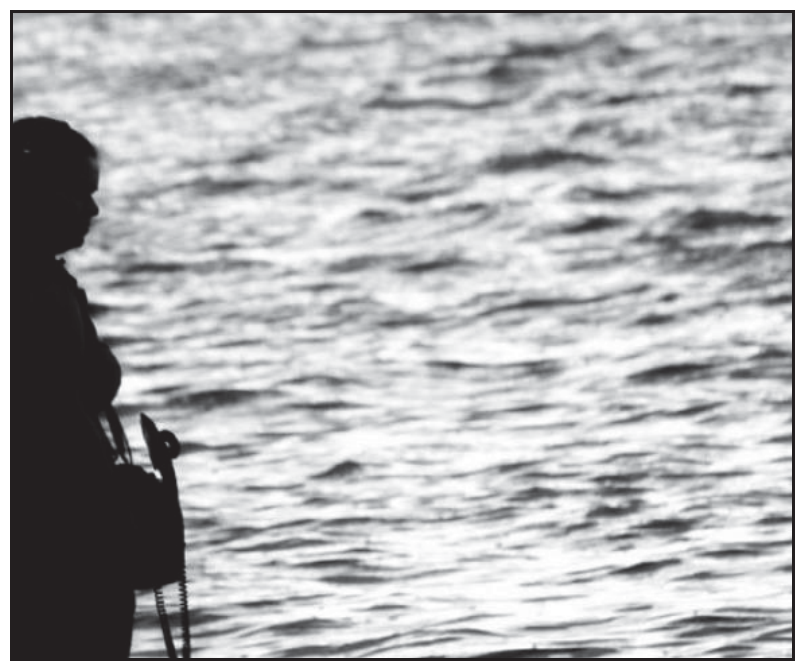

Figure 1: Leah Barclay Listening to the Amazon River

River Listening extends Barclay's recent work in soundscape ecology and aquatic bioacoustics in collaboration with the Australian Rivers Institute to explore emerging methodologies in the acoustic monitoring of river systems. River Listening is an interdisciplinary collaboration of freshwater ecology, virtual technologies, acoustic ecology and environmental sound art to explore methods of 
hydrophonic recording, soundscape analysis and virtual dissemination. The project draws on the Australian River Institute's existing work in freshwater bioacoustic monitoring (Linke, Gifford \& Kennard 2013).

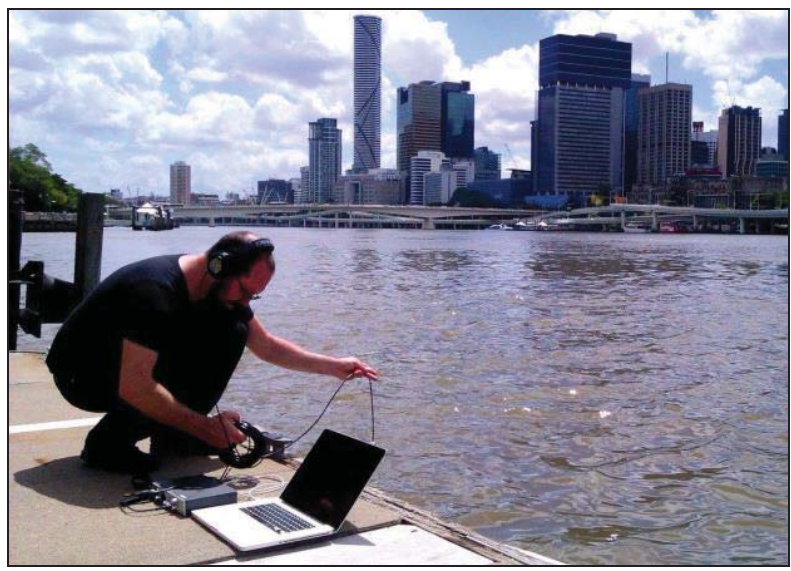

Figure 2: Fishing for Sounds in the Brisbane River

Despite the rapidly growing interest in these emerging auditory fields, there is yet to be standardised approaches to field recording and interpreting the data. While scientists have developed advanced software tools for species recognition, there is a growing need to consolidate the available tools and explore the value of listening to the data in new ways. There are also exciting possibilities to make this data available for a wider audience through digital technology and creative collaborations.

\section{LISTENING TO THE THAMES}

Look at the plan of London through the ages. What is it that has remained constant throughout? The river Thames. ... yet sadly, the city has until now looked away from its river rather than look at it (Sinha-Jordan 2005).

Since the dawn of agriculture, rivers have been central to civilisation, affording river cities such as London as thriving hubs of commerce. The health of a river and the community it supports are intertwined. We see and smell the river, yet what do we really know of its secrets below the surface? An open wound we may see, and a gangrenous decay we may smell, but who will hear if the river weeps?

Listening to the Thames explores real-time hydrophonics as a means to revealing the hidden world beneath the river surface. Drawing on 'holistic' bioacoustics approaches to ecosystem health assessment (Servik et al. 2014) it adopts a 'composerly' approach to creating compelling and informative audio-visualisations of the riverine environment.

\section{REFERENCES}

Anderson, K. A., et al. (2008) Soniferous fishes in the Hudson River. Trans. Am. Fish Soc. 137(2), 616-626.

Barclay, L. (2013) Sonic Ecologies: Exploring the Agency of Soundscapes in Ecological Crisis. Soundscape: The Journal of Acoustic Ecology, 12(1), 2013, $29-32$.

Craig, C., Diprose, G., and Seaborne, M., with Ellmers, C. \& Werner, A. (2009) London's Changing Riverscape: Panoramas from London Bridge to Greenwich, Frances Lincoln, London.

Eacott, J. (2012) Flood Tide. Live sonification performance, University Campus Suffolk and other venues. $\quad \mathrm{http}: / / \mathrm{www}$.informal.org/floodtide.htm (retrieved 18 February 2014).

Fontana, B. (2010) River Sounding: a journey through the hidden sound worlds of the River Thames. Multimedia installation at Somerset House, London, April - May 2010.

Krause, B. (2012) The Great Animal Orchestra: Finding the Origins of Music in the World's Wild Places. Hatchette Digital.

Linke, S., Gifford, T., and Kennard, M. (2013) Listening to the fish - Acoustic monitoring of freshwater biodiversity through audio signature recognition. In Proceedings of Listening in the Wild, Queen Mary University of London, June 2013.

Quin, D. (2002). Antarctica: Austral Soundscapes. Soundscape: the Journal of Acoustic Ecology, 3(2), 30-31.

Servik K (2014). Eavesdropping on Ecosystems. Science, 343(6173), 834-837.

Sinha-Jordan, S. (2005) From the Great Stink to Now: the Story of River Thames. http://www.lbhf.gov.uk/external/la21/stink.htm (retrieved 15 March 2005).

Tonolla, D, Vicenç A., Lorang M., Heutschi M., and Tockner K. (2010) A field-based investigation to examine underwater soundscapes of five common river habitats. Hydrological Processes, 24(22), 3146-3156. 